\title{
A novel indirect sweet defence in Brassicaceae: Structure and function of extrafloral nectaries in Brassica juncea
}

Running head: Extrafloral nectaries in Brassica juncea

Vartika Mathur $^{1,2}$, Roel Wagenaar ${ }^{1}$, Jean- Claude Caissard ${ }^{3,4,5}$, A. Sankara Reddy ${ }^{6}$, Louise E. M. Vet ${ }^{1,7}$, Anne- Marie Cortesero ${ }^{8}$, and Nicole M. van Dam ${ }^{9}$

${ }^{1}$ Department of Terrestrial Ecology, Netherlands Institute of Ecology (NIOO-KNAW), P.O. Box 50, 6700 AB Wageningen, The Netherlands

${ }^{2}$ Department of Zoology, Sri Venkateswara College, Benito Juarez Marg, Dhaula kuan, University of Delhi, Delhi- 110021, India

${ }^{3}$ Université de Lyon, F-42023, Saint-Etienne, France

${ }^{4}$ Université de Saint-Etienne, Jean Monnet, F-42000, Saint-Etienne, France

${ }^{5}$ Laboratoire BVpam, EA2061, 23 rue du Dr Paul Michelon, F-42000, Saint-Etienne, France

${ }^{6}$ Rai University, Saroda Post, Dholka Taluka, Ahmedabad District, Gujarat- 382260, India

${ }^{7}$ Laboratory of Entomology, Wageningen University, P.O. Box 8031, $6700 \mathrm{EH}$ Wageningen, The Netherlands

${ }^{8}$ UMR 1349 IGEPP, INRA, Agrocampus Ouest, University of Rennes 1, Campus de Beaulieu, Avenue du Général Leclerc, 35042 Rennes Cedex, France

${ }^{9}$ Radboud University, Institute for Water and Wetland Research, Department of Ecogenomics, Heyendaalseweg 135, 6525 AJ Nijmegen, The Netherlands

Correspondence: Vartika Mathur, Department of Zoology, Sri Venkateswara College, 
Benito Juarez Marg, Dhaula kuan, University of Delhi, Delhi- 110021, India; Phone number: +91 9810386575; Fax no. +91 11 24118535; E-mail: vmathur@svc.ac.in, vartika_m@yahoo.com 


\section{Abstract}

While nectaries are commonly found in flowers, some plants also form extrafloral nectaries on stems or leaves. Here we report, for the first time in the family Brassicaceae, extrafloral nectaries in Brassica juncea. The extrafloral nectar (EFN) was secreted from previously amorphic sites on stems, flowering stalks and leaf axils from the onset of flowering until silique formation. Transverse sections at the point of nectar secretion revealed a pocket-like structure whose opening was surrounded by modified stomatal guard cells. The EFN droplets were viscous and up to $50 \%$ of the total weight was sugars, $97 \%$ of which was sucrose in the five varieties of $B$. juncea examined. Threonine, glutamine, arginine and glutamate were the most abundant amino acids. EFN droplets also contained glucosinolates, mainly gluconapin and sinigrin. Nectar secretion was increased when the plants were damaged by chewing above- and belowground herbivores and sap-sucking aphids. Parasitoids of each herbivore species were tested for their preference, of which three parasitoids preferred EFN and sucrose solutions over water. Moreover, the survival and fecundity of parasitoids were positively affected by feeding on EFN. We conclude that EFN production in $B$. juncea may contribute to the indirect defence of this plant species.

Key words: Extrafloral nectaries, herbivore-induced responses, indirect defence, temporal induction, Indian mustard, parasitoids, Brassica juncea, Brassicaceae 


\section{Introduction}

Extrafloral nectaries are nectar-secreting parts of the plant surface other than flowers. These organs are not directly involved in pollination, and can be found on virtually all aboveground plant parts (Koptur, 1992, Oliveira \& Pie, 1998). Plants bearing extrafloral nectaries are widely distributed around the world. One hundred and fourteen plant families with more than 700 genera and 4,000 species of plants, including pteridophytes, gymnosperms and angiosperms are known to possess extrafloral nectaries to date (Keeler, 2008).

Extrafloral nectaries display a wide diversity in structure as well as composition of nectar between and within plant families. They may be found as structural outgrowths on the cuticle, or situated in the mesophyll of the plant. The simplest, and perhaps the more primitive nectaries are 'gestaltless', i.e., without any externally visible structure (FreyWyssling \& Häusermann, 1960, Zimmermann, 1932). These nectaries can only be identified as areas where nectar appears on the plant surface. Consequently, these amorphic nectaries are difficult to identify when no nectar is secreted, and may be strongly underreported. Commonly, the extrafloral nectar (EFN) is released through modified stomata that remain permanently open, or through specialized trichomes (de la Barrera \& Nobel, 2004, Schmid, 1988). Furthermore, many nectaries are characterized by a continuous cuticle present on the surface of the nectar epidermis that may have specialized pores called 'secretory pits' or narrow tubular interruptions called 'micro channels', through which nectar can be exuded. Alternatively, the cuticle might simply rupture as a result of built-up pressure to release nectar (Escalante-Pérez \& Heil, 2012). This structural and mechanistic diversity of extrafloral nectaries could be due to recurrent gain or loss events in the course of evolution, and diverse selective pressures on their functionality in different plant species (Heil, 2011).

Phloem supplies both floral and extrafloral nectaries. Consequently, the chemical composition of EFN may be essentially similar to that of phloem. EFN is mainly composed of sugars, but may also contain amino acids, and sometimes a blend of other compounds such as inorganic ions, proteins, lipids, organic acids, phenolics, alkaloids and terpenoids (Gonzalez-Teuber \& Heil, 2009). New compounds belonging to a variety of classes are still 
being discovered in EFN. Its composition differs in quality and quantity between different plant taxa and can be changed by biotic and abiotic stress factors in the environment (Heil, 2011, Nepi et al., 2009).

The ecological function of EFN has been controversial for quite some time. In the past two decades, many studies have shown that EFN can play an important role in constitutive and induced plant defences against herbivores (Heil, 2011, Heil et al., 2004, Holland, Chamberlain \& Miller, 2011, Lach, Hobbs \& Majer, 2009, Wackers \& Bezemer, 2003). Extrafloral nectaries act as indirect defences by providing an alternative food source for natural enemies of herbivores, such as parasitoids, predators and mutualistic ants. The presence of freely available carbohydrates and amino acids, along with other nutrients, makes EFN a wholesome nutritional resource for the natural enemies, thus enhancing the prospects of them staying on the plant. Ants may even protect food resources such as EFN, thereby removing herbivores from the plant (Bentley, 1976). EFN production may be increased when the plant is damaged by herbivores, and collectively with other direct and indirect defences, this adds to the defence strategies of the plant (Heil, 2008).

Although many families are known to have EFN, it has not been reported in the Brassicaceae (Keeler, 2008). Here we describe, for the first time, extrafloral nectaries in Brown/Indian mustard, Brassica juncea (L.) Czern., a species belonging to this family. We analyse the distribution and ultrastructure of these nectaries on the plant, and the chemical composition of the secreted EFN. We also experimentally investigate their possible ecological function by studying the induction of EFN production by the above- and belowground insect herbivores of $B$. juncea, belonging to different feeding guilds. Additionally, we test the attraction, survival and fecundity of the parasitoids of these herbivores on EFN to explore the possibility that EFN contributes to the indirect defence strategy of this plant species. 


\section{Materials and methods}

Experiments were performed when plants were approximately four weeks old and in stage 63 according to BBCH scale (Lancashire et al., 1991). EFN composition in five varieties of $B$. juncea and temporal dynamics of EFN induction when the plants were damaged by Spodoptera exigua were examined at NIOO-KNAW, Heteren (pre-Wageningen location), the Netherlands (NL). Studies on the temporal dynamics of EFN induction with insects of different feeding guilds as well as parasitoid preference and survival bioassays were performed in UMR BiO3P, University of Rennes, Rennes, France. Histochemical studies were done at the University Jean Monnet, Saint-Etienne, France.

\section{$\underline{\text { Plants }}$}

Seeds of five commonly grown varieties of $B$. juncea, viz., varuna, $P$. bold, $P$. bahar, $P$. agarni and JDG, were obtained from the Division of Genetics, IARI, New Delhi, India, and stored dry and in the dark at $10^{\circ} \mathrm{C}$. They were germinated on glass beads in water in $10 \times 10$ $\mathrm{cm}$ plastic containers with a clear plastic lid.

In $\mathrm{NL}$, the greenhouse was kept at $21^{\circ} \mathrm{C}$ during the day and $16^{\circ} \mathrm{C}$ at night, at $16 \mathrm{~h} / 8 \mathrm{~h} \mathrm{LD}$ conditions maintained by sodium lamps. Seven days later, seedlings were transferred to 1.8$\mathrm{L}$ pots, containing $1000 \mathrm{~g}$ peat soil-sand mixture (Lentse Potgrond no. 4, Lent, NL). From third week onwards, plants were supplied with 0.5 Hoagland solution (Hoagland \& Arnon, 1950) once a week. Plants were maintained at $65 \% \mathrm{RH}$ throughout their growth period, but were transferred to a climate chamber with $90 \% \mathrm{RH} 24 \mathrm{~h}$ prior to the experiments.

In Rennes, the plants were grown in a greenhouse at $20+/-2^{\circ} \mathrm{C} ; 65 \% \mathrm{RH} 16 \mathrm{~h} / 8 \mathrm{~h} \mathrm{LD}$ conditions and supplemented once with $4 \mathrm{~N}: 6 \mathrm{P}: 8 \mathrm{~K}$ and micronutrients fertilizer from the third week onwards. During third week, they were transferred to plant growth room with conditions similar to the greenhouse to acclimatize them prior to the experiments.

For histochemical studies, plants were grown in the greenhouse at Saint-Etienne University, France, at $21+/-2^{\circ} \mathrm{C} ; 60 \% \mathrm{RH} ; 12 \mathrm{~h} / 12 \mathrm{~h}$ LD conditions and supplied with $2 \mathrm{~N}: 6 \mathrm{P}: 7 \mathrm{~K}$ fertilizer. 
Induction and histochemical studies were conducted using the variety varuna. Sugar and amino acid composition of EFN was analysed using varuna, $P$. bold, P. bahar, $P$. agarni and $J D G$ and glucosinolate composition was determined using P. bold, P. bahar, P. agarni and JDG.

\section{$\underline{\text { Insects }}$}

Insect cultures were maintained in a climate room at $27^{\circ} \mathrm{C}, 50-70 \% \mathrm{RH}$, and $16 \mathrm{~h} / 8 \mathrm{~h} \mathrm{LD}$ photoperiod. P. brassicae, M. persicae and D. radicum and its parasitoid, T. rapae were used from the culture maintained in UMR BiO3P, University of Rennes. $D$. radicum and $T$. rapae were reared according to Neveu, Kacem and Nénon (1996). M. persicae was reared on $B$. nigra and $P$. brassicae was reared on $B$. oleracea plants. Cocoons of $C$. glomerata (parasitoid of $P$. brassicae) and Di. rapae (parasitoid of $M$. Persicae) were obtained from NIOO-KNAW, NL and University of Rennes, France, respectively. S. exigua was obtained from Wageningen University, NL, and maintained on artificial diet (Vickerman \& Trumble, 1999). The cocoons of its parasitoid, C. marginiventris, were obtained from University of Neuchâtel, Switzerland. Parasitoid females were used in the experiments within $24 \mathrm{~h}$ of emergence.

\section{EFN Collection}

Experiments were conducted within $24 \mathrm{~h}$ of appearance of EFN on plants. As the amount of EFN produced per plant was too small to be weighed accurately, EFN produced by one group of five plants was pooled. For each treatment group $(n=15)$, plants were divided into three groups of five approximately similarly sized plants, unless mentioned otherwise.

EFN was viscous and could not be collected using capillaries. Therefore the droplets were absorbed using two circles punched out of Whatman filter paper no. 1 for each treatment group. These papers were weighed on Mettler-Toledo MT5 Electro balance (accuracy $\pm 1 \mu \mathrm{g}$ ) prior to and after EFN collection. Thereafter, the filter paper was immersed in $1.5 \mathrm{ml}$ MilliQ water and allowed to remain at room temperature for one hour so that nectar would dissolve 
in water. The Eppendorf tubes were stored at $-20^{\circ} \mathrm{C}$ until further analysis. Total EFN collected was determined by calculating the difference between the weights before and after the collection from each group. The average EFN per plant was determined by dividing the total of a group by 5 .

\section{$\underline{\text { Histochemical methods }}$}

To study the structure of tissue that secretes EFN, paradermal sections were observed beneath droplets directly by photonic microscopy (Leitz DMRB microscope). For transverse sections, the area was marked around the droplet using a marker pen and cut manually with a razor blade. Fresh sections were stained with Toluidine blue O (Parker, Haskins \& DeyrupOlsen, 1982) or with Rawlins-Takashashi reaction (Rawlins \& Takahash, 1952) to identify the tissues. Stem surface was observed by ESEM after drying the droplets with a tissue. Stem samples were laid on a stage fitted to the low-pressure chamber of an S-3000N Hitachi microscope (Tokyo, Japan). To allow ESEM observations, samples were cooled from $4^{\circ} \mathrm{C}$ to a minimum of $-20^{\circ} \mathrm{C}$ by the Pelletier effect. Pressure was then set at $110 \mathrm{~Pa}$ and tension at $15 \mathrm{kV}$.

\section{EFN composition}

Sugar and amino acid analysis was performed according to van Dam and Oomen (2008). For soluble sugars, analysis was done on Dionex HPLC system, using a Carbopac PA1 column (2 x $250 \mathrm{~mm})$ and a Carbopac PA1 guard column $(2 \times 50 \mathrm{~mm})$ (Dionex). Separation of sugars was done with isocratic gradient mixture of $10 \% 1 \mathrm{M} \mathrm{NaOH}$ and $90 \%$ MilliQ water at a flow rate of $0.25 \mathrm{ml}$ per min.

Amino acid concentration was analysed on a Dionex HPLC system by integrated pulsed amperometric detection. Amino acids were separated with a ternary gradient on a $2 \times 50 \mathrm{~mm}$ AminoPac( PA10 column with a 2 x 50 mm AminoPac@ PA10 Guard column (Dionex). Sigma AAS- 18 amino acid standard (Sigma) containing 18 amino acids was supplemented 
with asparagine, glutamine and tryptophan $\left(2.5 \mu\right.$ moles $\mathrm{ml}^{-1}$ each) to obtain a reference sample containing the 20 most common amino acids.

For glucosinolate analysis, EFN was collected from five plants of approximately similar size and dissolved in $1 \mathrm{ml}$ water in an Eppendorf tube and frozen at $-20^{\circ} \mathrm{C}$ till further analysis. Ten such samples were pooled together to obtain one biological replicate. Three such biological replicates were made per cultivar. Each sample was directly added to a DEAESephadex A-25 column (5x10mm). The column was washed twice with $1 \mathrm{ml} 70 \% \mathrm{MeOH}$, once with $1 \mathrm{ml}$ MilliQ and then twice with $1 \mathrm{ml} 20 \mathrm{mM} \mathrm{NaOAC}$ buffer (pH 5.5). $20 \mu \mathrm{L}$ of aryl sulfatase (Sigma type $\mathrm{H}-1$ of Helix pomatia) was added to the columns and flushed down with $50 \mu \mathrm{L} \mathrm{NaOAC}$ buffer. The columns were then covered with aluminium foil and incubated overnight at room temperature. Thereafter, desulfoglucosinolates were eluted from the columns with $0.75 \mathrm{ml}$ MilliQ water twice, and freeze-dried. The residue was redissolved in 1 $\mathrm{ml}$ of MilliQ water and stored in $-20^{\circ} \mathrm{C}$ deep freezer until further analysis.

Glucosinolates were analysed according to van Dam, Witjes and Svatos (2004) using a photodiode array detector with the integration wavelength of $229 \mathrm{~nm}$ (Dionex, Sunnyvale, CA, USA). Desulfoglucosinolate peaks were identified by comparison of retention times and UV spectra with a certified rape seed standard (Community Bureau of Reference, Brussels, code BCR-367R) and authentic standards (progoitrin, gluconapin, glucoiberin, glucobrassicanapin, glucotropeaolin, gluconasturtiin, glucoraphanin, glucoerucin, glucobrassicin, sinalbin; Phytoplan, Heidelberg, Germany).

Results of the analysis were calculated back to the mass of collected nectar in order to calculate the sugar, amino acid and glucosinolate concentrations in EFN.

\section{$\underline{\text { Time course of induction }}$}

Plants were divided into four groups for damaged and control treatments. Each group contained five approximately similarly-sized plants $(n=20)$. EFN droplets were removed with the help of a filter paper prior to the experiment. A single fourth instar $S$. exigua larva was 
introduced in a clip cage on the fourth leaf counted from the apex of the plant at noon and readings were taken every 8 hours for the first two days. After that, EFN was collected every 16 hours till EFN production had ceased. Control groups received empty clip cages. Groups of damaged and undamaged plants were arranged randomly. The larvae remained on the plants for the whole experimental period.

\section{Induction by insects of different feeding guilds}

EFN droplets were removed using a filter paper prior to the experiment. A single fourth instar S. exigua or P. brassicae larva was placed in a clip cage on the fourth leaf counted from the apex of the plant. When the larvae had eaten most of the leaf, they were transferred to another leaf of the plant. Five-third instar larvae of $D$. radicum were placed onto the soil surface using a brush adjacent to the roots of each plant. Plants were examined 30 minutes later to ensure that all the larvae had moved into the soil. Ten nymphs of $M$. persicae were introduced to the fourth leaf of the plant but they were not restricted by any means, and were allowed to move freely on the plant. Each day the number of aphids was counted and new aphids were added to compensate for any losses.

Control groups of plants with $S$. exigua and $P$. brassicae treatments received empty clip cages and with $M$. persicae and $D$. radicum treatments were left as they were. The larvae remained on the plants for the whole experimental period. EFN was collected every $24 \mathrm{~h}$ for five consecutive days after the insects were introduced.

\section{$\underline{\text { Parasitoid preference }}$}

Prior to the experiment, $0-24 \mathrm{~h}$ old naive females of $C$. marginiventris $(\mathrm{n}=51), C$. glomerata $(\mathrm{n}=115), T$. rapae $(\mathrm{n}=98)$ and Di. rapae $(\mathrm{n}=64)$ (where $\mathrm{n}$ represents the total number of parasitoids tested including those who did not make a choice) were collected after emergence and separated individually into vials. During the experiment, $5 \mu \mathrm{L}$ droplets of water, EFN and sucrose solution were placed equidistant from each other in a $6 \mathrm{~cm}$ diameter Petridish. The sucrose solution prepared was of the same concentration as that of EFN to 
keep the sugar content similar, i.e. $300 \mu$ EFN (which constitutes $150 \mu$ g sucrose as shown in the earlier experiment), dissolved in $100 \mu \mathrm{L}$ of water or $150 \mu \mathrm{g}$ of sucrose powder dissolved in $100 \mu \mathrm{L}$ of water. Parasitoids were released individually in the centre of the Petridish. The first droplet on which they started feeding was recorded as their choice. Each female was observed for a maximum of 15 minutes or until her first choice, whichever was earlier, after which she was removed from the Petridish. Females that did not respond within this time frame were put in the "no decision" category and were discarded from the experiment. The positions of the droplets in the Petridish were changed between each replicate to avoid positional bias.

\section{Parasitoid survival and fecundity}

The experiment was conducted in a climate room $\left(19^{\circ} \mathrm{C}, 50-60 \% \mathrm{RH}, 16 \mathrm{~h} / 8 \mathrm{~h} \mathrm{LD}\right)$. A total of 15 parasitoids per species were tested per treatment group. In the first $24 \mathrm{~h}$ after emergence, parasitoids were placed individually in a Petridish of $9 \mathrm{~cm}$ diameter containing $10 \mu \mathrm{L}$ of either EFN or sucrose solution as was prepared for the parasitoid preference experiment. The control group received $10 \mu \mathrm{L}$ of water. The following day, all the parasitoids were provided only with water in moist cotton until the end of the experiment. Survival of the parasitoids was scored daily.

For determining fecundity, females of $C$. marginiventris and $T$. rapae were dissected after they died in the survival experiment and the number of eggs in the ovaries was counted using a compound microscope.

\section{Statistical analysis}

Data were analysed using SPSS 17.0 (SPSS, Chicago, IL, USA) unless stated otherwise. Normality and homogeneity of variance for all the data obtained were determined using onesample Kolmogorov-Smirnov test and Levene's test, respectively. 
Based on EFN collected from plants of $B$. juncea var varuna $(n=171)$, there was no correlation found between plant weight and absolute weight of EFN (Pearson Correlation; $P$ $>$ 0.05). Therefore, we present the absolute amount per plant throughout this paper. Concentration of sugars and glucosinolates were compared using univariate ANOVA and the concentration of amino acids was compared using non parametric Kruskal- Wallis test. The overall amount of EFN induced and its sugar content in plants damaged by $S$. exigua were analysed using repeated measure ANOVA and individual time points were analysed using $t$ tests with sequential Bonferroni corrections (Holm, 1979). Induction of EFN due to damage by herbivores was analysed using repeated measure ANOVA and the effect of Days and Days $x$ Damage was tested on EFN production. Amount of EFN on individual days following damage by different herbivores was tested using independent-sample $t$-test. Orientation of parasitoids between water, EFN and sucrose solution was analysed using a non-parametric Chi- square test.

Survival analysis was conducted by using the R software R Development Core Team (2011), additional R packages 'survival' (Therneau \& Lumley, 2009) and RVAideMemoire (Hervé, 2011). Influence of diet on parasitoid survival was assessed by using a Cox proportionalhazards regression model. Each species was fitted into a model. Proportionality of hazards was tested and assumed for all four models. For each species, treatment effect was assessed by a one-way deviance analysis and a chi-square test. When treatment had a significant effect on female survival, pairwise comparisons between EFN, sucrose and water were performed by using the log-rank test. $P$-values were adjusted using BenjaminiHochberg correction. Parasitoid fecundity data was analysed using univariate ANOVA with Bonferroni corrections. 


\section{Results}

\section{Morphology and anatomy}

Under sufficient light conditions, EFN droplets were secreted in $B$. juncea at the onset of flowering when plants were at stage 63 according to $\mathrm{BBCH}$ scale (Lancashire et al., 1991). These nectaries were found on the plant stem, peduncles and in leaf axils (Figure 1a and b). Secretion started at the flowering stage and continued for 5-8 days until silique formation. The average weight of these droplets $(n=230)$ was $0.28 \pm 0.02 \mathrm{mg}$. Occasionally droplets weighing more than $2 \mathrm{mg}$ were found. The total mass of EFN droplets on plants was the highest on the first day of their appearance, and decreased with each successive removal. EFN secretion was observed in the greenhouse in NL and France and under field conditions in Delhi-India (V. Mathur and N. M. van Dam, personal observations) between October and February, which is the typical growing season of mustard in India.

Nectar droplets were gently wiped from the stem and the epidermis underneath was observed under Environmental Scanning Electron Microscope (ESEM). We found a pore that looked like modified stomata, whose guard cells were always opened, in contrast to typical stomata that were closed (Figure 2). Paradermal peelings observed by light microscopy revealed a lack of green parenchyma in this area. A pocket-like structure of around $50 \mu \mathrm{m}$ diameter was observed in the transverse sections passing through the pore (Figure $3 \mathrm{a}$ and b). However, Toluidine blue $\mathrm{O}$ and Rawlins-Takahashi staining on the stem anatomy did not provide a detailed picture of the connection between this structure and xylem or phloem.

\section{EFN Composition}

Analysis of five commonly grown varieties of $B$. juncea, viz., varuna, Pusa bold, P. bahar, $P$. agarni and JDG, showed that both EFN sugar and amino acid compositions were comparable in all these varieties. Sugars accounted for almost $50 \%$ of the EFN weight in all five varieties and were similar in concentration (Univariate ANOVA; $F_{(4,115)}=1.799, P>$ 
0.05). Sucrose dominated the sugar composition, accounting for almost $97 \%$ of the total sugars. The less abundant sugars in EFN found were glucose (ca. 1.7\%), fructose (ca. $0.9 \%$ ) and traces of manitol, sorbitol and trehalose (Table 1). Amongst amino acids, threonine and glutamine were the highest in all varieties tested. Glutamate and arginine were also abundant (Table 2). In contrast to sugars, the concentration of total amino acids differed significantly between varieties (Kruskal-Wallis test; $H_{4}=12.295, P=0.015$ ). Additionally, we analysed glucosinolates, which are the main secondary compounds in Brassicaceae, in Pusa bold, P. bahar, P. agarni and JDG. The total concentration of glucosinolates was about $2.42 \pm 0.25 \mu \mathrm{mol} / \mathrm{mg}$ of EFN and was similar in all four varieties (Univariate ANOVA; $F_{(3,8)}=8.44, P>0.05$ ). Gluconapin (ca. $75 \%$ ) and sinigrin (ca. $22 \%$ ), with traces of glucobrassicanapin and gluconasturtiin, were the main constituents of glucosinolates in EFN.

\section{$\underline{\text { Time course of EFN induction after generalist damage }}$}

Nectar was collected repeatedly at $8 \mathrm{~h}$-intervals for the first $48 \mathrm{~h}$ to determine the temporal dynamics of nectar secretion in plants damaged with the leaf-chewing generalist Spodoptera exigua larvae compared to undamaged plants. Thereafter, because EFN production decreased with time, the sampling was continued every $16 \mathrm{~h}$, until EFN production ceased. A repeated measures ANOVA determined that average mass of EFN $(\mu \mathrm{g})$ secreted per plant differed significantly over time (Greenhouse-Geisser corrected, Time, $F_{(1.549,9.291)}=7.867, P$ $=0.013)$. This was mainly due to a decrease in nectar secretion at later time points and not due to any particular diurnal pattern in EFN production (Figure 4a). Even though EFN production was on an average always higher in damaged plants, and significantly so at $64 \mathrm{~h}$ ( $t$-test with sequential Bonferroni corrections $\left.t_{6}=4.950, P=0.03\right)$, there was no overall statistical difference in EFN production due to damage (Greenhouse-Geisser corrected, Damage, $\left.F_{(1.549,9.291)}=1.037, P=0.372\right)$. Overall there was no significant change in $E F N$ sugar concentration due to damage (Greenhouse-Geisser corrected, Damage, $F_{(3.169,19.016)}=$ 1.318, $P>0.05)$ (Figure 4b). 
$\underline{\text { Induction by herbivores of different feeding guilds }}$

The amount of EFN produced was compared between intact plants and plants damaged by different above- or belowground herbivores every $24 \mathrm{~h}$ for five consecutive days. Since this experiment was conducted in different environmental conditions from the time course experiment performed in $\mathrm{NL}$, damage by $S$. exigua was repeated to verify the consistency of the response. A repeated measure ANOVA revealed that aboveground damage by leafchewing specialist Pieris brassicae larvae $\left(F_{(4,16)}=4.030, P=0.019\right)$ or the generalist aphid Myzus persicae (ANOVA, $F_{(4,16)}=5.308, P=0.006$ ) as well as by the root feeding specialist Delia radicum larvae $\left(F_{(4,16)}=3.856, P=0.022\right)$ increased EFN production. When analysed for individual days, P. brassicae induced EFN on two days [day 1 (uncorrected independent sample $t$-test; $\left.t_{6}=-5.500, P=0.005\right)$; day $\left.3\left(t_{6}=-3.500, P=0.025\right)\right]$. EFN production increased on three days following damage by $M$. persicae [day $2\left(t_{6}=-4.914, P=0.008\right)$; day $3\left(t_{6}=-5.000, P=0.007\right)$; day $\left.4\left(t_{6}=-3.536, P=0.024\right)\right]$. Interestingly, EFN was not induced by $D$. radicum at individual time points. When damaged by the leaf-chewing generalist $S$. exigua, EFN was not significantly induced over the period of study, although a significant effect of damage was seen on day 1 (uncorrected independent sample $t$-test; $t_{6}=-0.400, P=$ 0.016). In addition, for $M$. persicae $\left(F_{(4,16)}=7.205, P=0.001\right)$ there was an interaction between day and damage. This interaction was not significant for the other insects studied (Figure 5).

\section{$\underline{\text { Parasitoid preference }}$}

When a choice between water, EFN and sucrose was presented to the parasitoids of each of the tested herbivores, a significant preference of EFN and sugar over water was shown by Cotesia glomerata, the parasitoid of $P$. brassicae $\left[X_{(2)}^{2}=11.511, P=0.003\right]$ and Trybliographa rapae, the parasitoid of $D$. radicum $\left[X^{2}{ }_{(2)}=9.056, P=0.011\right]$. A trend for EFN preference was shown by Diaeretiella rapae, the parasitoid of $M$. persicae, but this preference was not significant $\left[X_{(2)}^{2}=5.286, P=0.071\right]$. Cotesia marginiventris, the 
parasitoid of $S$. exigua, did not show any preference for the solutions offered $\left[X^{2}{ }_{(2)}=0.483, P\right.$ $=0.786]($ Figure 6).

\section{Parasitoid survival and fecundity}

Survival of $C$. marginiventris (Survival analysis, $\left.X_{(2)}^{2}=23.274, P<0.001\right), C$. glomerata $\left(X^{2}{ }_{(2)}\right.$ $=22.914, P<0.001)$ and Di. rapae $\left(X^{2}{ }_{(2)}=11.779, P<0.005\right)$ was affected by diet. The survival of $T$. rapae, on the other hand, was not affected $\left(X^{2}{ }_{(2)}=1.329, P=0.5144\right)$. The survival rates of $C$. marginiventris females showed significant differences in the pairwise comparisons between EFN, sucrose and water (Log-rank test, $P<0.001$ ). On the other hand, females survived equally well on EFN and sucrose in the case of $C$. glomerata $(P=$ $0.5073)$ and $\mathrm{Di}$. rapae $(P=0.699)$, but both performed significantly better on EFN and sucrose than on water $(P<0.0001)$ (Figure 7$)$.

The fecundity of two of these parasitoids $(n=15)$, viz., C. marginiventris and $T$. rapae, was determined after they died in the survival experiment. In C. marginiventris, the number of eggs in the ovaries were significantly higher when fed on EFN $(166.80 \pm 1.73)$ or sucrose $(168.27 \pm 0.89)$ on the first day after emergence than in those fed only on water their whole life $\left(156.67 \pm 1.88\right.$; ANOVA; $F_{(2,42)}=16.337, P<0.001$, Bonferroni post-hoc analysis, sucrose versus water, and EFN versus water both $P<0.001)$. We found a similar trend in T. rapae with egg loads higher for females that were offered sucrose $(99.60 \pm 0.98)$ or EFN $(94.00 \pm 2.07)$ and as compared to those offered water $\left(91.13 \pm 2.61\right.$; ANOVA; $F_{(2,42)}=$ 4.597, $P<0.05$, Bonferroni post-hoc analysis, sucrose versus water, $P=0.014$ ) (Supplementary figure 1). 


\section{Discussion}

Our study reports, for the first time, the occurrence of EFN in B. juncea. The family Brassicaceae, to which $B$. juncea belongs, has not been known to possess extrafloral nectaries before (Keeler, 2008). These nectaries are found on the stem, peduncles and in leaf axils, and secrete nectar that predominantly contains sugars. Ultrastructural studies showed that these nectaries are formed as pocket-like structures in the epidermis of the stem-only just before the onset of flowering. EFN secretion began at the flowering stage and continued till silique formation. Feeding activities of three of the four above- and belowground herbivores tested enhanced the amount of secreted nectar. Parasitoid arrestment, survival and fecundity were enhanced by EFN, thus suggesting a possible ecological role of the EFN as an indirect defence.

The closest relative of Brassicaceae that possess extrafloral nectaries is Capparis retusa (Order Brassicales, family Capparaceae), where the nectaries look like umbilicated glands containing a specialized parenchyma vascularized with xylem and phloem (Di Sapio, Gattuso \& Prado, 2001). Moreover, floral nectaries in many species of Brassicaceae have been described as protuberant gland structures surrounded by a modified stomata, which maintain a firm contact between cells and subjacent parenchyma cells (Baum, Eshed \& Bowman, 2001, Davis, Peterson \& Shuel, 1986, Davis et al., 1998, Davis et al., 1994). In contrast, the structure of extrafloral nectaries in $B$. juncea is a pocket-like cavity beneath the modified stomata (Figure $3 a$ and b). A few species like Citrus limon (Rutaceae) and Sambucus nigra (Adoxaceae) are known to possess nectaries with a pocket-like cavity (Fahn, 1979, Fahn, 1988), but such nectaries have not been described in the order Brassicales (Elias, 1983, Keeler, 2008, Nepi, 2007). The modified stomata surrounding the extrafloral nectaries in $B$. juncea are common in most floral and extrafloral nectaries. These stomata are always open and hence do not regulate nectar secretion (Bernardello, 2007, Elias, 1983, Escalante-Pérez \& Heil, 2012, Heil, 2011, Nepi, 2007). The formation of pocketlike cavities in $B$. juncea could either be by cell lysis or by modification of the substomatal 
chamber. Future work in this direction could provide better insight into the ontogeny of these cavities.

Previous studies have demonstrated that EFN may either show a diurnal pattern by an increase in secretion at certain day times (Heil et al., 2000), or a constant secretion irrespective of the time of the day (Bentley, 1976). We found the nectaries in $B$. juncea secreted small amounts of nectar throughout the day and there was no diurnal rhythm. However, in separate studies, plants failed to produce nectar in climate cabinets with lower light intensity or quality. The importance of light intensity was confirmed by the fact that these plants began to produce EFN when moved from the growth cabinets to the greenhouse (V. Mathur and N. M. van Dam, unpublished data). Thus, although no diurnal pattern was observed, light quality could play a significant role in EFN production.

EFN is known to attract and sustain ants, parasitoids and predators, and thus serves as an indirect defence against herbivores (Heil, 2008, Koptur, 1992, Rudgers, 2004, Yamashiro \& Yamashiro, 2008). Carbohydrates and free amino acids in the nectar are important for their attraction. Floral and extrafloral nectar sugar concentrations range from $8 \%$ to $80 \%$ depending on the plant species, but may also vary with environmental conditions (Nicolson \& Nepi, 2005, Nicolson \& Thornburg, 2007, Pacini \& Nepi, 2007). EFN produced by B. juncea was viscous and around $50 \%$ of the total weight of EFN was sugars in all the varieties examined (Table 1). This concentration is similar to that observed for its floral nectar (Masierowska, 2003). Sucrose was the main sugar present in B. juncea EFN (ca. $97 \%$ of the total sugars). It is well known that sucrose is the preferred carbohydrate for carbon transfer in the phloem and $95 \%$ of total sugars in phloem sap are sucrose (Yeo \& Flowers, 2007). In Brassicaceae, floral nectar is richer in hexoses, indicating that processing of the phloemtransported sugars takes place before it is excreted (Baker \& Baker, 1983, Percival, 1961). However, EFN in B. juncea predominantly contained sucrose, and therefore we assume that the nectar is being directly secreted from phloem, despite the lack of visual connections between phloem and nectaries in the transverse sections. 
In addition to sugars, amino acids may also play an important role in the attractiveness of nectar, even when they are about 100 to 1,000 times less concentrated than sugars (Heil, 2011). Amino acids have been reported in foliar nectar of pteridophytes, as well as floral and extrafloral nectar of angiosperms. Serine, glycine, alanine, arginine and proline are typically abundant in these secretions (Baker \& Baker, 1983, Pate et al., 1985). However, in the EFN of $B$. juncea, threonine, glutamine, arginine and glutamate were the most abundant amino acids. Besides sugars and amino acids, other compounds like volatiles, proteins, lipids and several classes of secondary metabolites have been reported in nectar (Gonzalez-Teuber \& Heil, 2009, Kessler \& Baldwin, 2007, Nicolson \& Thornburg, 2007). In our study, the EFN in B. juncea contained glucosinolates, which are prominent secondary compounds in Brassicaceae, conferring resistance not only to insects (Hopkins, van Dam \& van Loon, 2009), but also to microbes (Bressan et al., 2009). The glucosinolate profile was found to be essentially similar to that found in the leaves of $B$. juncea in an earlier study (Mathur et al., 2011). Possibly glucosinolates aid in keeping the nectar sterile, but they may also prevent the entry of phytopathogens from the permanently opened nectary pores (Heil, 2011).

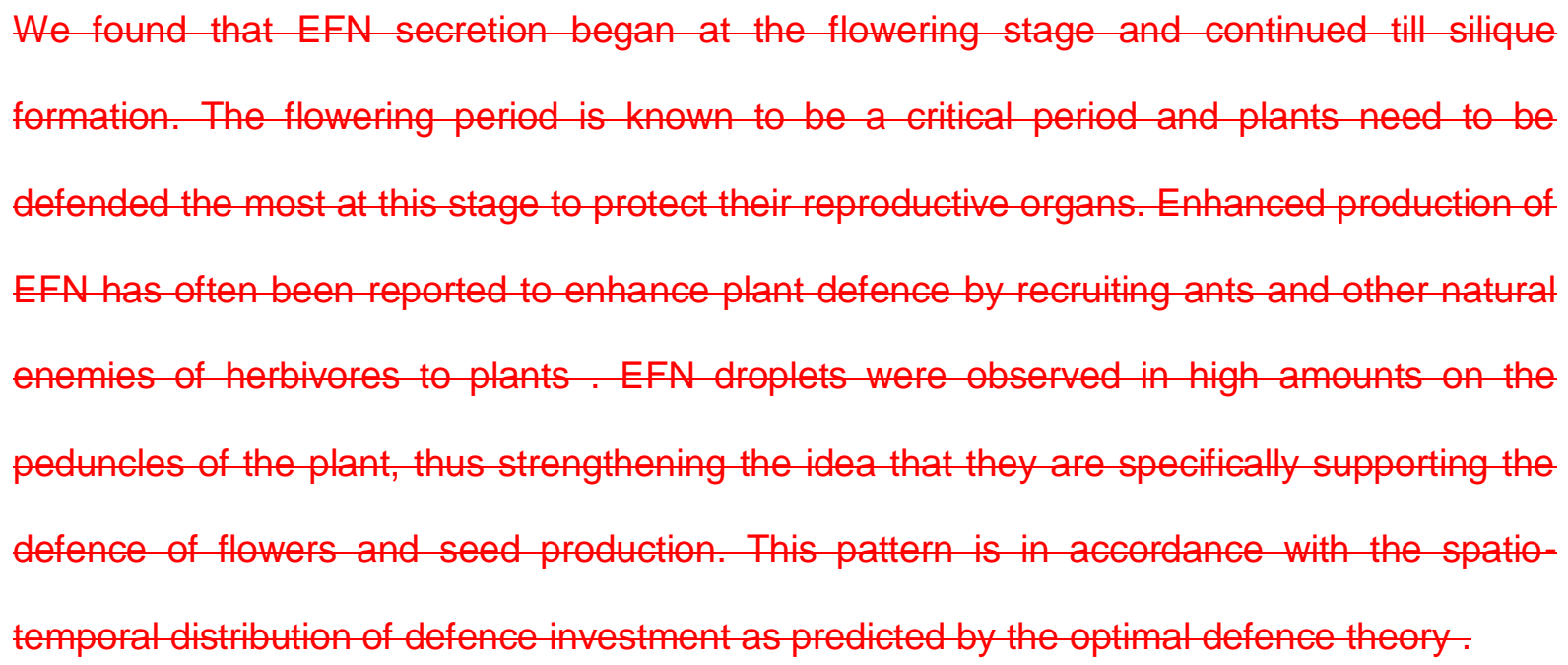
formation. The flowering period is known to be a critical period and plants need to be defended the most at this stage to protect their reproductive organs. Enhanced production of EFN has often been reported to enhance plant defence by recruiting ants and other natural enemies of herbivores to plants. EFN droplets were observed in high amounts on the peduncles of the plant, thus strengthening the idea that they are specifically supporting the defence of flowers and seed production. This pattern is in accordance with the spatiotemporal distribution of defence investment as predicted by the optimal defence theory.

Plants increase EFN production as an indirect defence when they are damaged by root or shoot herbivores (Escalante-Pérez \& Heil, 2012, Heil, 2004, Wackers \& Bezemer, 2003). EFN production in $B$. juncea was also found to be influenced by herbivory. Nectar secretion was increased by chewing above- and belowground herbivores, but also by sap sucking 
herbivores. However, thisWe found that EFN induction varied temporally with the feeding insect species. This indicates a degree of specificity in the EFN secretion to different herbivores. However, further studies would be needed to assess differences in the herbivore feeding responsible for this specificity.

Most of the earlier studies have been done in the context of ant-plant interactions (Bentley, 1976, Bixenmann, Coley \& Kursar, 2011, Heil et al., 2001), but several studies have also addressed the role of EFN in the attraction of parasitoids (Lewis et al., 1998, Rose, Lewis \& Tumlinson, 2006, Stapel et al., 1997). To attain a high reproductive success, the disruption of parasitoid's host foraging process should be minimal so that most of its time and energy can be allocated to finding hosts and producing offspring. In our study, C. glomerata and $T$. rapae showed a significant preference for EFN and Di. rapae showed a similar trend, emphasizing the possible importance of EFN in parasitoid attraction and retention on $B$. juncea plants. In contrast, C. marginiventris did not prefer either of the choices offered. This lack of statistically significant response may be due to low number of responding parasitoids. Resource finding in parasitoids is typically interplay between an attractant stimulus, that causes them to orientate towards the source, and an arrestant stimulus due to which they reduce/stop searching behaviour (Dethier, Browne \& Smith, 1960). Here, we observed that the orientation of parasitoids was more associated with arrestment than with attraction. The assumption also arises from our finding that parasitoids were equally attracted to EFN and sucrose solution. It is known that experienced parasitoids associate the odours with the presence of hosts (Turlings \& Wäckers, 2004, Vet, Lewis \& Carde, 1995). However, whether parasitoids can perceive EFN from distance is still unknown (Rose et al., 2006).

By secreting EFN, plants provide parasitoids with a rich carbohydrate resource on the plant itself, and thus an opportunity to live and forage longer on the plant. In our survival analysis, three of the tested parasitoids survived significantly longer when fed on EFN or sucrose just for one day, as compared to parasitoids that were given water only. Longevity is directly proportional to the quality of carbohydrate consumed by the parasitoid (Giron, Pincebourde 
\& Casas, 2004, Wackers, 2001). EFN in B. juncea consists of $97 \%$ sucrose, which is known to be a good carbohydrate source of carbohydrate (Wackers, 2001, Wäckers, 2003). Thus, our study suggests that EFN from $B$. juncea may act as a high nutritional quality resource for parasitoids. Interestingly, the glucosinolates in EFN only seemed to have a significant effect on the survival of the generalist parasitoid C. marginiventris, which survived longer on sugar water than on EFN (Figure 7a). Specialized parasitoids of specialist Brassica herbivores were not affected by glucosinolates in the EFN, which may reflect their adaptation to these typical Brassica defences that may also be present in their herbivorous hosts (Hopkins et al., 2009). Additionally, the survival rate of $T$. rapae was similar on all three treatments. T. rapae, being a pro-ovigenic parasitoid, is known to reabsorb its eggs to fulfil its nutritional requirements and live longer under low nutrient conditions (Jervis et al., 2001). However, previous field studies have found $T$. rapae lived longer when provided with floral nectar throughout their lives (Nilsson et al., 2011). On examination of the ovaries of $C$. marginiventris and $T$. rapae after the survival experiment, we found that the potential fecundity of both parasitoids was higher after feeding on EFN on the first day than when they were given only water. This suggests that EFN was-is a nutritious food source for these parasitoids, thus underscoring the fact that parasitoids may have a longer life span and a higher fecundity when feeding on EFN.

The extrafloral nectaries observed in B. juncea are initially amorphic and the nectarsucrose was more abundant in the sucrosenectar, as in phloem, than in-hexose sugars, ${ }_{2}$ as in its-floral nectar. Based on the hypotheses regarding the evolution of (floral) nectar secretion proposed by de la Barrera and Nobel (2004), we speculate that the leaky phloem hypothesis of the origin of nectar can be applied to thesethe B. juncea nectaries. However, the physiological mechanism by which this is achieved needs to be investigated before drawing a final conclusion. there are two plausible mechanisms explaining the origin of the amorphic extrafloral nectaries in B. juncea: the leaky phloem hypothesis and the sugar excretion hypothesis. According to the first, nectar secretion may have originated as leakage of 
phloem solution, resulting from the structural weakness of developing tissues exposed to high pressure in the phloem. The sugar excretion hypothesis suggests that the solute accumulation resulting from the relatively high transpiration rates of flowers results in nectar secretion to dispose of excess solutes. The extrafloral nectaries observed in B. juncea are initially amorphic and the nectar was more abundant in sucrose, as in phloem, than in hexose sugars as in its floral nectar. Therefore, we speculate that the leaky phloem hypothesis of the origin of nectar can be applied to these nectaries. However, the physiological mechanism by which this is achieved needs to be investigated before drawing a final conclusion.

The development of extrafloral nectaries in $B$. juncea may have a role in the tritrophic interaction among plants, herbivores and parasitoids. With this study, we described the presence of EFN in B. juncea, a novel insight in the defence strategies employed by Brassicaceae plant species. We showed that the nectar is inducible and that plant response varies with herbivore species, thus showing some degree of specificity. EFN and that it could be used by several natural enemies of the main herbivore species of this plant both aboveand belowground. Further field studies are required to understand the evolution and ecological significance of these extrafloral nectaries as indirect defences. Our first description of these extrafloral nectaries therefore does not provide final answers, but may serve as a starting point for future research on the ecological role of EFN secretion by this plant species. Most importantly, it should be assessed whether the timing and inducibility of $\underline{\text { the EFN excretions contribute to increasing plant fitness. Possibly, } t \text { This knowledge will also }}$ contribute to the development of better biological control practices and hence more sustainable agricultural practices for $B$. juncea production. 


\section{Acknowledgement}

We acknowledge Dr. P.S. Pierre, V. Chaminade, C. Josso (Rennes, France), C. Casper, O. Calf $(\mathrm{RU}, \mathrm{NL})$, I. Anselme-Bertrand (Saint-Etienne Electron Microscopy Center, France), Dr. M.N.V.P. Gajula (PRI, NL) and G. Disveld (NIOO-KNAW, NL) for their practical assistance. Thanks to M. Hervé (Rennes, France) for advice in statistics, S. Dourlot (Rennes, France) for EFN pictures and Dr. L. Pierson (RU, NL) for earlier versions of EM pictures of nectaries. We thank Dr. M. Erb (MPI-CE, Germany) and L. Westerd (WUR, NL) for providing $C$. marginiventris and S. exigua, respectively. We express thanks to Dr. T.O.G. Tytgat (RU, NL) for his critical comments. This research was funded by grants to Vartika Mathur from Nuffic (Netherlands Organization for International Cooperation in Higher Education) in NL and European Mobility grant by the International Doctoral College of the European University of Brittany (CDI-UEB) in France. 


\section{References}

Baker H.G. \& Baker I. (1983) A brief historical review of the chemistry of floral nectar. In: The biology of nectaries (eds B. Bentley \& T. Elias), pp. 126-152. Columbia University Press, New York.

Baum S.F., Eshed Y. \& Bowman J.L. (2001) The Arabidopsis nectary is an ABC-independent floral structure. Development, 128, 4657-4667.

Bentley B.L. (1976) Plants bearing extrafloral nectaries and the associated ant community: interhabitat differences in the reduction of herbivore damage. Ecology, 815-820.

Bernardello G. (2007) A systematic survey of floral nectaries. In: Nectaries and Nectar. (eds S.W. Nicolson, M. Nepi, \& E. Pacini), pp. 19-121. Springer, Dordrecht.

Bixenmann R.J., Coley P.D. \& Kursar T.A. (2011) Is extrafloral nectar production induced by herbivores or ants in a tropical facultative ant-plant mutualism? Oecologia, 165, 417-425.

Bressan M., Roncato M.A., Bellvert F., Comte G., Haichar F.E., Achouak W. \& Berge O. (2009) Exogenous glucosinolate produced by Arabidopsis thaliana has an impact on microbes in the rhizosphere and plant roots. Isme Journal, 3, 1243-1257.

Davis A.R., Peterson R.L. \& Shuel R.W. (1986) Anatomy and vasculature of the floral nectaries of Brassica napus (Brassicaceae). Canadian Journal of Botany, 64, 2508-2516.

Davis A.R., Pylatuik J.D., Paradis J.C. \& Low N.H. (1998) Nectar-carbohydrate production and composition vary in relation to nectary anatomy and location within individual flowers of several species of Brassicaceae. Planta, 205, 305-318.

Davis A.R., Sawhney V.K., Fowke L.C. \& Low N.H. (1994) Floral nectar secretion and ploidy in Brassica rapa and Brassica napus (Brassicaceae).1. Nectary size and nectar carbohydrate production and composition. Apidologie, 25, 602-614.

de la Barrera E. \& Nobel P. (2004) Nectar: properties, floral aspects, and speculations on origin. Trends Plant Sci, 9, 65-69.

Dethier V.G., Browne L.B. \& Smith C.N. (1960) The designation of chemicals in terms of the responses they elicit from insects. Journal of Economic Entomology, 53, 134-136.

Di Sapio O.A., Gattuso M.A. \& Prado D.E. (2001) Structure and development of the axillary complex and extrafloral nectaries in Capparis retusa Griseb. Plant Biology, 3, 598-606.

Elias T.S. (1983) Extrafloral nectaries: their structure and distribution. In: The Biology of Nectaries. (eds B. Bentley \& T. Elias), pp. 174-203. Columbia University Press, New York.

Escalante-Pérez M. \& Heil M. (2012) Nectar Secretion: Its Ecological Context and Physiological Regulation. In: Signaling and Communication in Plants (eds J.M. Vivanco \& F. Baluška). Springer-Verlag Berlin Heidelberg, .

Fahn A. (1979) Secretory tissues in plants. London, New York, San Francisco.: Academic Press.

Fahn A. (1988) Secretory- tissues in vascular plants. New Phytologist, 108, 229-257.

Frey-Wyssling A. \& Häusermann E. (1960) Deutung der gestaltlosen Nektarien. Berichte schweitzerische botanishe gesellschaft, 70, 150-162.

Giron D., Pincebourde S. \& Casas J. (2004) Lifetime gains of host-feeding in a synovigenic parasitic wasp. Physiological Entomology, 29, 436-442.

Gonzalez-Teuber M. \& Heil M. (2009) Nectar chemistry is tailored for both attraction of mutualists and protection from exploiters. Plant signaling \& Behavior, 4, 809-813.

Heil M. (2004) Induction of two indirect defences benefits Lima bean (Phaseolus lunatus, Fabaceae) in nature. Journal of Ecology, 92, 527-536.

Heil M. (2008) Indirect defence via tritrophic interactions. New Phytologist, 178, 41-61.

Heil M. (2011) Nectar: generation, regulation, and ecological functions. Trends in Plant Science, 16, 191-200.

Heil M., Fiala B., Baumann B. \& Linsenmair K. (2000) Temporal, spatial and biotic variations in extrafloral nectar secretion by Macaranga tanarius. Functional Ecology, 14, 749-757.

Heil M., Greiner S., Meimberg H., Krüger R., Heubl. G., Noyer J.-L., Linsenmair K.E. \& Boland W. (2004) Evolutionary change from induced to constitutive expression of an indirect plant resistance. Nature, 430, 205-208. 
Heil M., Koch T., Hilpert A., Fiala B., Boland W. \& Linsenmair K.E. (2001) Extrafloral nectar production of the ant-associated plant, Macaranga tanarius, is an induced, indirect, defensive response elicited by jasmonic acid. Proceedings of the National Academy of Sciences of the USA, 98, 1083-1088.

Hervé M. (2011) Diverse basic statistical and graphical functions accompanying the French book 'Aide-memoire de statistique appliquee a la biologie'. In: $R$ package version 0.9-5.

Hoagland D.R. \& Arnon D.I. (1950) The water culture method for growing plants without soil. Bulletin of the Californian Agricultural Experiment Station, 347, 1-32.

Holland J.N., Chamberlain S.A. \& Miller T.E.X. (2011) Consequences of ants and extrafloral nectar for a pollinating seed-consuming mutualism: ant satiation, floral distraction or plant defense? Oikos, 120, 381-388.

Holm S. (1979) A simple sequentially rejective multiple test procedure. Scandinavian Journal of Statistics, 6, 65-70.

Hopkins R.J., van Dam N.M. \& van Loon J.J.A. (2009) Role of glucosinolates in insect-plant relationships and multitrophic interactions. Annual Review of Entomology, 54, 57.

Jervis M.A., Heimpel G.E., Ferns P.N., Harvey J.A. \& Kidd N.A.C. (2001) Life-history strategies in parasitoid wasps: a comparative analysis of 'ovigeny'. Journal of Animal Ecology, 70, 442458.

Keeler K. (2008) World list of angiosperms with extrafloral nectaries. See http://bsweb.unl.edu/Emeriti/keeler/extrafloral/Cover.htm.

Kessler D. \& Baldwin I.T. (2007) Making sense of nectar scents: the effects of nectar secondary metabolites on floral visitors of Nicotiana attenuata. Plant Journal, 49, 840-854.

Koptur S. (1992) Plants with extrafloral nectaries and ants in everglades habitats. Florida Entomologist, 75, 38-50.

Lach L., Hobbs R.J. \& Majer J.D. (2009) Herbivory-induced extrafloral nectar increases native and invasive ant worker survival. Population Ecology, 51, 237-243.

Lancashire P.D., Bleiholder H., Vandenboom T., Langeluddeke P., Stauss R., Weber E. \& Witzenberger A. (1991) A uniform decimal code fo growth-stages of crops and weeds. Annals of Applied Biology, 119, 561-601.

Lewis W.J., Stapel J.O., Cortesero A.M. \& Takasu K. (1998) Understanding how parasitoids balance food and host needs: Importance to biological control. Biological Control, 11, 175-183.

Masierowska M.L. (2003) Floral nectaries and nectar production in brown mustard (Brassica juncea) and white mustard (Sinapis alba) (Brassicaceae). Plant Systematics and Evolution, 238, 97107.

Mathur V., Ganta S., Raaijmakers C.E., Reddy A.S., Vet L.E.M. \& van Dam N.M. (2011) Temporal dynamics of herbivore-induced responses in Brassica juncea and their effect on generalist and specialist herbivores. Entomologia Experimentalis Et Applicata, 139, 215-225.

Nepi M. (2007) Nectary structure and ultrastructure. In: Nectaries and nectar (eds S.W. Nicolson, M. Nepi, \& E. Pacini), pp. 129-166. Springer, Dordrecht.

Nepi M., von Aderkas P., Wagner R., Mugnaini S., Coulter A. \& Pacini E. (2009) Nectar and pollination drops: how different are they? Annals of Botany, 104, 205-219.

Neveu N., Kacem N. \& Nénon J.P. (1996) A method for rearing Trybliographa rapae W. on Delia radicum L. OILB/SROP Bulletin, 19, 173-178.

Nicolson S.W. \& Nepi M. (2005) Dilute nectar in dry atmospheres: Nectar secretion patterns in Aloe castanea (Asphodelaceae). International Journal of Plant Sciences, 166, 227-233.

Nicolson S.W. \& Thornburg R.W. (2007) Nectar chemistry. In: Nectaries and Nectar (eds S.W. Nicolson, M. Nepi, \& E. Pacini), pp. 215-264. Springer, Dordrecht.

Nilsson U., Rannback L.M., Anderson P., Eriksson A. \& Ramert B. (2011) Comparison of nectar use and preference in the parasitoid Trybliographa rapae (Hymenoptera: Figitidae) and its host, the cabbage root fly, Delia radicum (Diptera: Anthomyiidae). Biocontrol Science and Technology, 21, 1117-1132. 
Oliveira P.S. \& Pie M.R. (1998) Interaction between ants and plants bearing extrafloral nectaries in cerrado vegetation. Anais Da Sociedade Entomológica Do Brasil, 27, 161-176.

Pacini E. \& Nepi M. (2007) Nectar production and presentation. In: Nectaries and Nectar (eds S.W. Nicolson, M. Nepi, \& E. Pacini), pp. 169-216. Springer, Dordrecht.

Parker A.J., Haskins E.F. \& Deyrup-Olsen I. (1982) Toluidine Blue: A Simple, Effective Stain for Plant Tissues. The American Biology Teacher, 487-489.

Pate J.S., Peoples M.B., Storer P.J. \& Atkins C.A. (1985) The extrafloral nectaries of cowpea (Vignaunguiculata (L) Walp) II. Nectar composition, origin of nectar solutes, and nectary functioning. Planta, 166, 28-38.

Percival M.S. (1961) Types of nectar in angiosperms. New Phytologist, 60, 235-281.

Rawlins T. \& Takahash W. (1952) Technics of plant histochemistry and virology. The National Press, Mitlbrae, Calif.

Rudgers J.A. (2004) Enemies of herbivores can shape plant traits: Selection in a facultative ant-plant mutualism. Ecology, 85, 192-205.

Schmid R. (1988) Reproductive versus extra-reproductive nectaries - historical perspective and terminological recommendations. Botanical Review, 54, 179-232.

Stapel J.O., Cortesero A.M., De Moraes C.M., Tumlinson J.H. \& Lewis W.J. (1997) Extrafloral nectar, honeydew, and sucrose effects on searching behavior and efficiency of Microplitis croceipes (Hymenoptera: Braconidae) in cotton. Environmental Entomology, 26, 617-623.

Team R.D.C. (2011) R: A language and environment for statistical computing. R Foundation for Statistical Computing, Vienna, Austria.

Therneau T. \& Lumley T. (2009) Survival: Survival analysis, including penalised likelihood. $R$ package version, 2.

van Dam N.M. \& Oomen W.A.T. (2008) Root and shoot jasmonic acid applications differentially affect leaf chemistry and herbivore growth. Plant Signaling \& Behaviour, 3, 91-98.

van Dam N.M., Witjes L. \& Svatos A. (2004) Interactions between aboveground and belowground induction of glucosinolates in two wild Brassica species. New Phytologist, 161, 801-810.

Vickerman D.B. \& Trumble J.T. (1999) Feeding preferences of Spodoptera exigua in response to form and concentration of selenium. Archives of Insect Biochemistry and Physiology, 42, 64-73.

Wackers F.L. (2001) A comparison of nectar- and honeydew sugars with respect to their utilization by the hymenopteran parasitoid Cotesia glomerata. Journal of Insect Physiology, 47, 10771084.

Wäckers F.L. (2003) The parasitoids' need for sweets: sugars in mass rearing and biological control. In: Quality control and production of biological control agents: theory and testing procedures (ed v.L. J.C.), pp. 59-72. CAB International, Wallingford, UK.

Wackers F.L. \& Bezemer T.M. (2003) Root herbivory induces an above-ground indirect defence. Ecology Letters, 6, 9-12.

Yamashiro A. \& Yamashiro T. (2008) Utilization on extrafloral nectaries and fruit domatia of Canavalia lineata and C-cathartica (Leguminosae) by ants. Arthropod-Plant Interactions, 2, 18.

Yeo A.R. \& Flowers T.J. (2007) Plant solute transport. John Wiley and Sons, New Jersey.

Zimmermann J. (1932) Über die extrafloren nektarien der Angiospermen. Beihefte Botanisches Zentralblatt, 49, 99-196. 
Table 1: Mean \pm SE $(\mu \mathrm{g} / \mathrm{mg}$ of EFN) of sugar constituents in the extrafloral nectar collected from five varieties of $B$. juncea plants viz varuna, $P$. bold, $P$. bahar, $P$. agarni and JDG. ND: not detected

$\begin{array}{lrrcrc} & \text { Varuna } & P . \text { bold } & \text { P. Bahar } & P . \text { Agarni } & \text { JDG } \\ \text { sorbitol } & 0.01 \pm 0.01 & 0.03 \pm 0.02 & \text { ND } & 0.03 \pm 0.03 & \text { ND } \\ \text { manitol } & 0.26 \pm 0.02 & 0.26 \pm 0.02 & 0.27 \pm 0.01 & 0.24 \pm 0.03 & 0.29 \pm 0.01 \\ \text { trehalose } & \mathrm{ND} & 0.03 \pm 0.02 & \mathrm{ND} & 0.03 \pm 0.02 & \mathrm{ND} \\ & & & & & \\ \text { glucose } & 5.80 \pm 0.95 & 11.33 \pm 2.87 & 12.17 \pm 1.90 & 8.62 \pm 1.66 & 8.73 \pm 1.47 \\ \text { fructose } & 2.86 \pm 0.74 & 6.33 \pm 1.81 & 5.95 \pm 1.62 & 4.63 \pm 1.18 & 5.34 \pm 1.26 \\ & & & & & \\ \text { sucrose } & 528.81 \pm 14.77 & 550.24 \pm 13.62 & 533.49 \pm 9.21 & 488.43 \pm 22.17 & 557.56 \pm 4.74 \\ \text { Total sugars } & 537.73 \pm 14.87 & 568.21 \pm 14.02 & 551.89 \pm 9.75 & 501.97 \pm 22.67 & 571.92 \pm 5.03\end{array}$


Table 2: Mean \pm SE $(\mu M)$ of amino acid constituents in the extrafloral nectar collected from five varieties of $B$. juncea plants viz varuna, $P$. bold, $P$. bahar, $P$. agarni and JDG. ND: not detected

Varuna

P. Bold

P. bahar

P. agarni

$64.25 \pm 9.27$

Arginine

$25.32 \pm 3.91$

$41.02 \pm 5.48$

$33.41 \pm 5.44$

$7.70 \pm 1.33$

$17.45 \pm 2.46$

$17.06 \pm 3.16$

$25.67 \pm 3.94$

$15.72 \pm 2.23$

Glutamine

$29.95 \pm 3.76$

$51.58 \pm 6.28$

$62.54 \pm 7.18$

$90.48 \pm 11.04$

$53.75 \pm 6.81$

Asparigine

$9.23 \pm 1.75$

$21.23 \pm 3.01$

$22.41 \pm 3.89$

$34.81 \pm 5.24$

$22.56 \pm 3.02$

Alanine

$11.77 \pm 2.35$

$22.24 \pm 3.33$

$16.41 \pm 2.81$

$32.39 \pm 4.21$

$19.84 \pm 2.94$

Threonine

$24.23 \pm 3.89$

$75.52 \pm 13.04$

$94.97 \pm 18.11$

$140.99 \pm 37.04$

$64.02 \pm 7.95$

Glycine

$0.65 \pm 0.22$

$0.74 \pm 0.15$

$0.81 \pm 0.20$

$26.07 \pm 24.50$

$0.70 \pm 0.15$

Valine

$12.13 \pm 2.13$

$23.60 \pm 3.25$

$23.00 \pm 4.03$

$38.09 \pm 5.32$

$22.71 \pm 3.08$

Serine

$14.72 \pm 2.57$

$27.64 \pm 3.97$

$26.73 \pm 4.36$

$46.66 \pm 6.08$

$30.31 \pm 4.13$

Proline

$15.97 \pm 3.86$

$30.11 \pm 3.83$

$26.67 \pm 4.79$

$50.40 \pm 6.56$

$20.17 \pm 3.15$

Isoleucine

ND

ND

ND

ND

ND

Leucine

$1.62 \pm 0.34$

$3.36 \pm 0.65$

$5.21 \pm 1.08$

$3.23 \pm 0.73$

$4.96 \pm 0.71$

Methionine

$0.64 \pm 0.15$

$1.27 \pm 0.20$

$1.67 \pm 0.33$

$1.86 \pm 0.30$

$1.61 \pm 0.29$

Histidine

$4.10 \pm 0.71$

$8.70 \pm 1.19$

$8.69 \pm 1.45$

$12.28 \pm 1.61$

$8.23 \pm 1.11$

Phenylalanine

$4.45 \pm 0.81$

$7.79 \pm 1.13$

$7.28 \pm 1.20$

$11.99 \pm 1.56$

$7.90 \pm 1.15$

Glutamate

$17.51 \pm 3.35$

$46.33 \pm 6.57$

$48.22 \pm 7.76$

$69.68 \pm 9.07$

$43.04 \pm 6.03$

Aspartate

$6.21 \pm 1.14$

$12.39 \pm 1.92$

$15.95 \pm 2.72$

$27.69 \pm 3.61$

$14.10 \pm 2.03$

Cystine

$0.01 \pm 0.01$

ND

ND

$0.02 \pm 0.02$

ND 


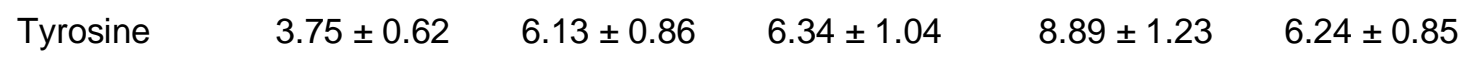

$\begin{array}{llllll}\text { Tryptophan } & 1.09 \pm 0.20 & 1.99 \pm 0.31 & 1.80 \pm 0.34 & 2.41 \pm 0.38 & 1.77 \pm 0.27\end{array}$

Total AA $\quad 191.05 \pm 66.81399 .12 \pm 50.43 \quad 419.16 \pm 84.94 \quad 687.88 \pm 115.29367 .15 \pm 45.56$ 
Figure 1. Extrafloral nectar (EFN) in Brassica juncea. EFN is secreted from the stem, peduncles and in leaf axils of the plant between the flowering stage until silique formation. (C) S. Dourlot, University of Rennes 1, UMR IGEPP).

Figure 2. Front view of Brassica juncea epidermis through ESEM at the site of EFN droplet (a) modified open stomata; (b) wider view of (a) with closed stomata; (c) a modified stomata and a typical closed stomata. Arrows: modified stomata; arrow heads: pore of the modified stomata; dashed arrows: closed stomata. Asterisks indicate a nectar droplet residue. Scale bars $20 \mu \mathrm{m}$.

Figure 3. Transversal sections of extrafloral nectaries stained with Toluidine Blue $O$ (a) Pocket-like structures are concealed deep within the stem (b) These structures are guarded by an modified stomata (arrow) and secrete nectar by an open pore (arrow head). Ep: epidermis; Cr: cortical parenchyma. Scale bars $100 \mu \mathrm{m}$.

Figure 4: Temporal induction of (a) EFN ( $\mu \mathrm{g})$ and (b) sugars $(\mu \mathrm{g} / \mathrm{mg}$ of EFN) per plant of Brassica juncea $(n=20)$ after damage by Spodoptera exigua. Asterisks indicate significant induction at individual time points due to damage (independent sample $t$ - test; $P<0.05$ ). Numbers in parentheses represent the hours elapsed since the start of the experiment.

Figure 5: Temporal induction of EFN $(\mu \mathrm{g})$ per plant of Brassica juncea $(n=15)$ after damage by insects of different feeding guilds. A horizontal line above the graph indicates a significant induction over time (repeated measures ANOVA) due to damage by (a) Spodoptera exigua $(P>0.05)(b)$ Pieris brassicae $(P=0.001)(c)$ Myzus persicae $(P=0.013)(d)$ Delia radicum $(P=0.017)$. Asterisks indicate significant induction at individual time points due to damage (independent sample $t$ - test; ${ }^{*} \mathrm{P}<0.05 ;{ }^{*} \mathrm{P}<0.01$ ).

Figure 6. Orientation response of naive females of (a) Cotesia marginiventris $(n=29)(b) C$. glomerata $(n=94)$ (c) Trybliographa rapae $(n=89)$ (d) Diaeretiella rapae $(n=56)$ when offered a choice between water, sucrose and EFN. Preference was significant for $C$. glomerata (chi-square test; $P=0.011)$ and $T$. rapae $(P=0.003)$. Numbers in parentheses 
represent the number of females which did not make a decision and hence were excluded from calculations.

Figure 7: Survival curves of parasitoids $(n=15)$ when offered $10 \mu \mathrm{L}$ of water, sucrose or EFN for the first $24 \mathrm{~h}$ after emergence. Data was analysed using survival analysis (a) Cotesia marginiventris $(P<0.001)$, (b) C. glomerata $(P<0.001)$, (c) Diaeretiella rapae $(P<0.005)$, (d) Trybliographa rapae $(P=0.5144)$.

\section{Supplementary Figure 1: Mean ( \pm SE) of the fecundity of (a) Cotesia marginiventris and (b)}

Trybliographa rapae when fed with water, sucrose or EFN for 24 h after emergence $(n=15)$.

a

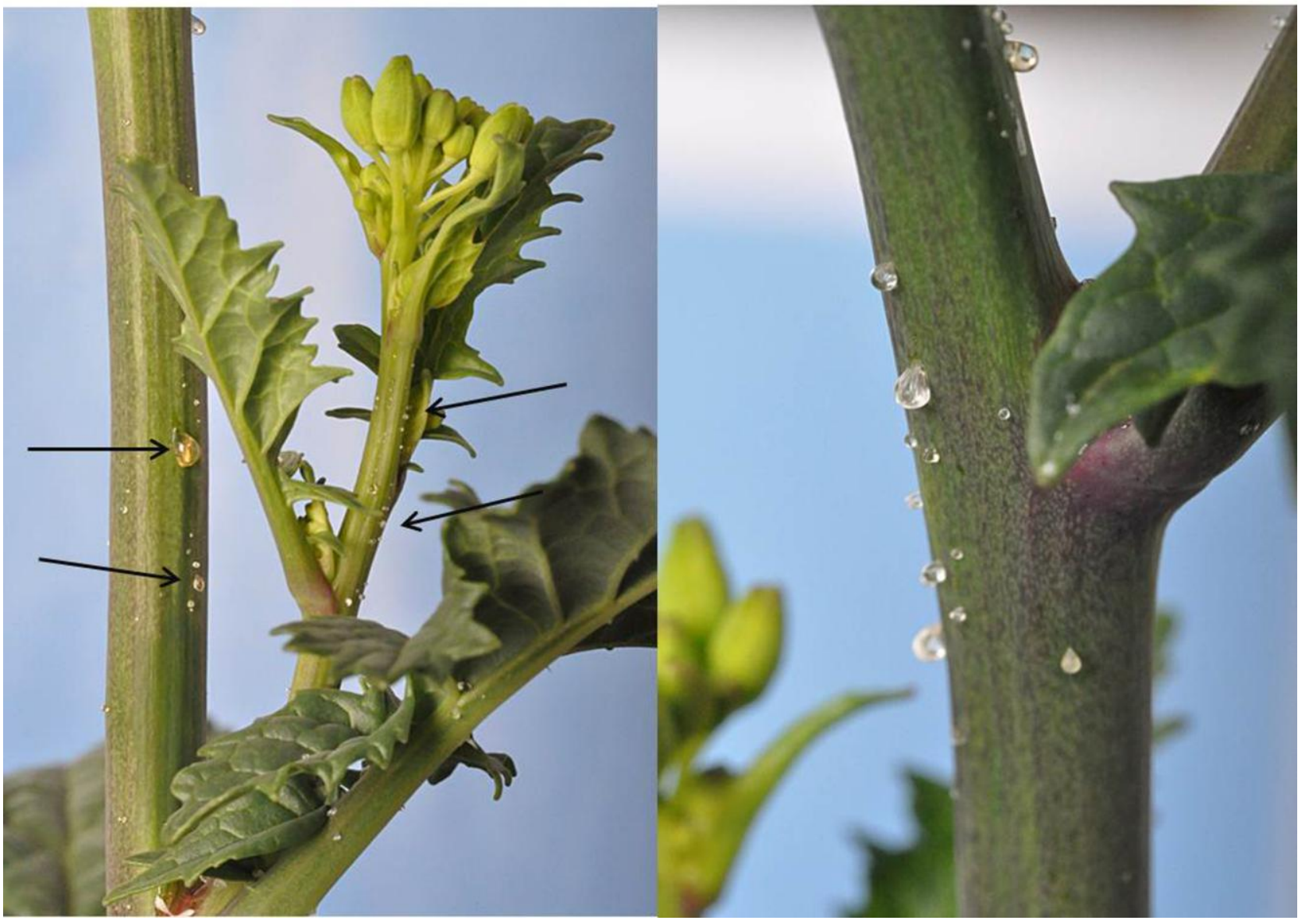



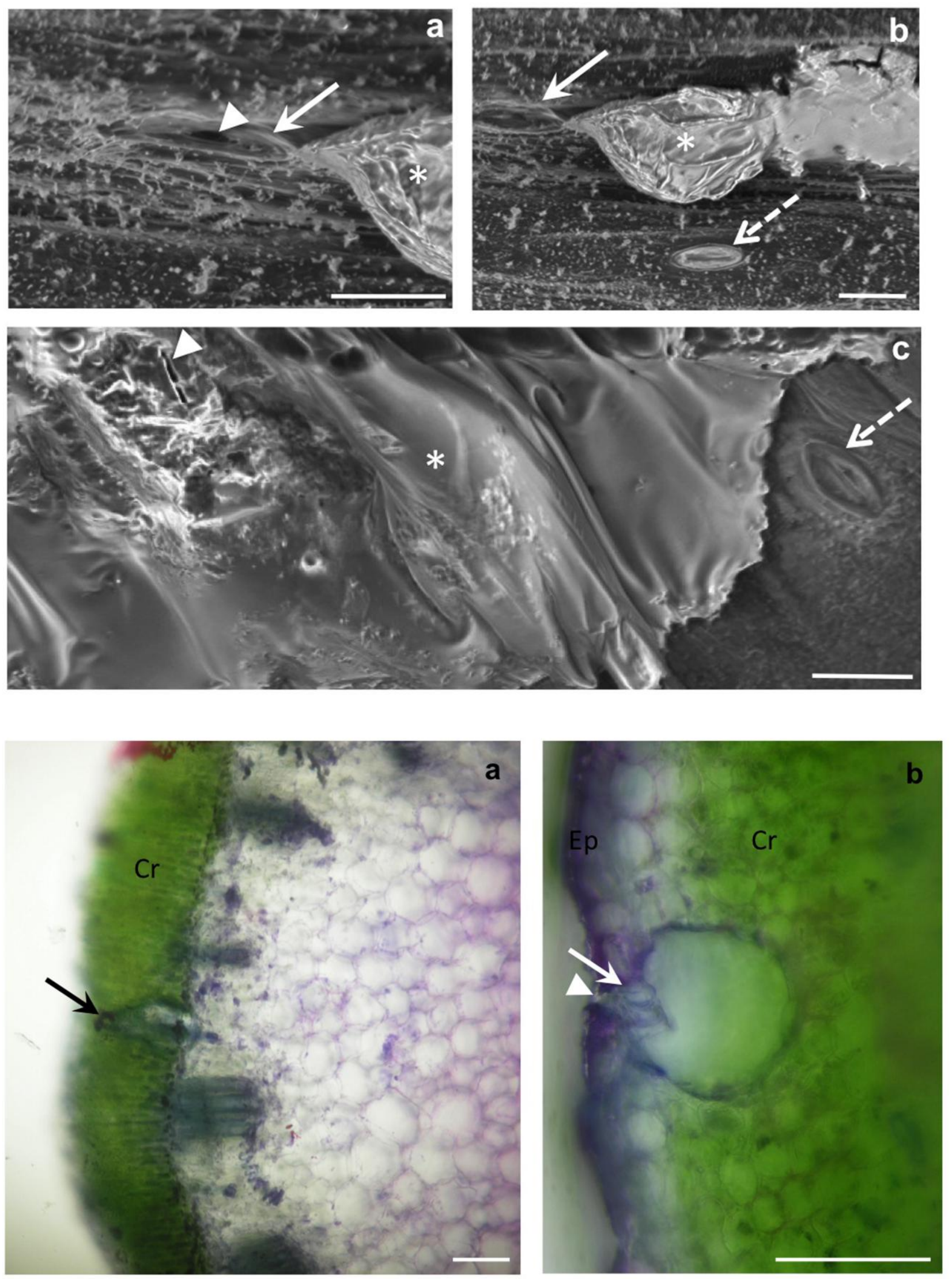

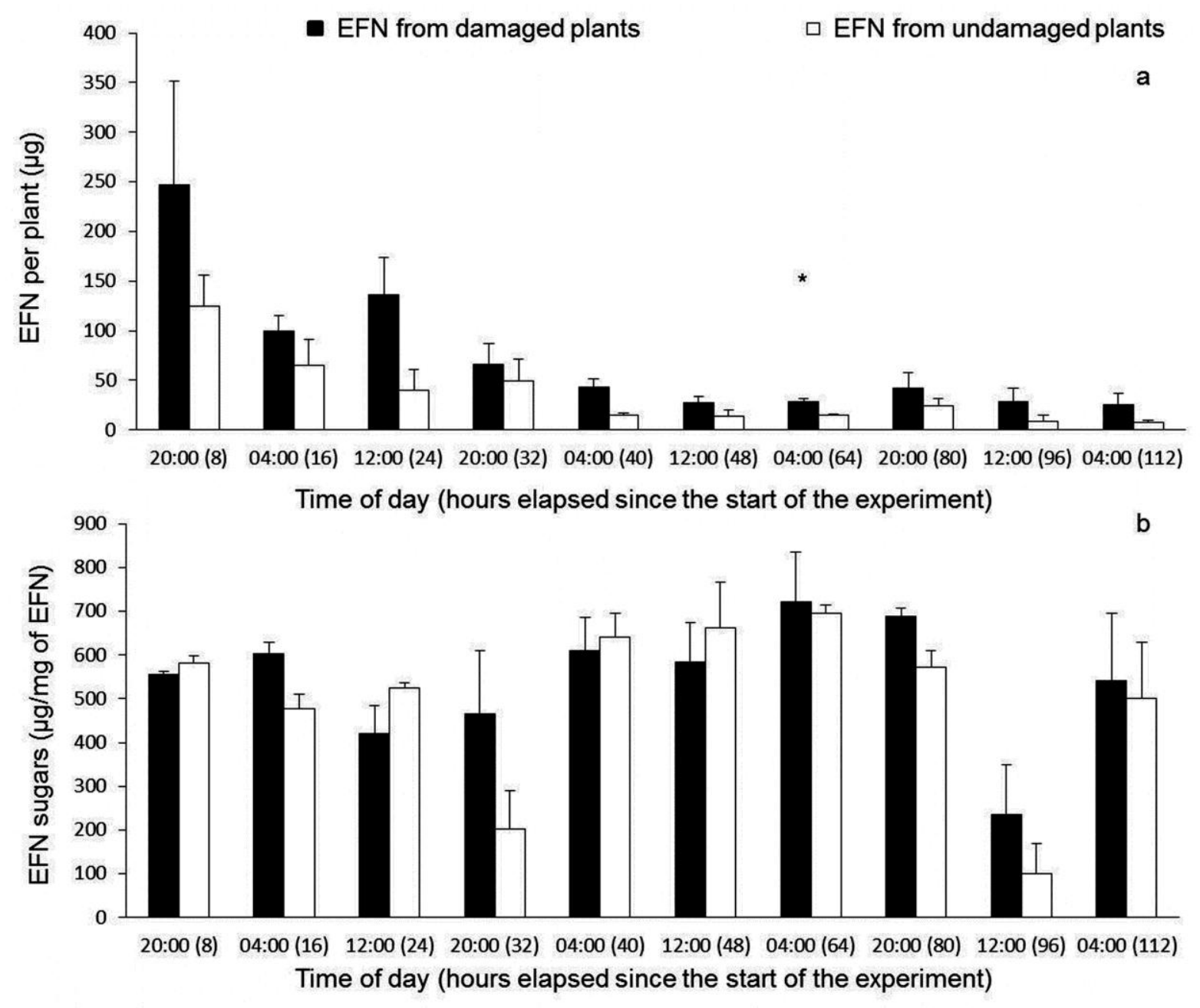
- EFN from damaged plants

a. Damage by Spodoptera exigua
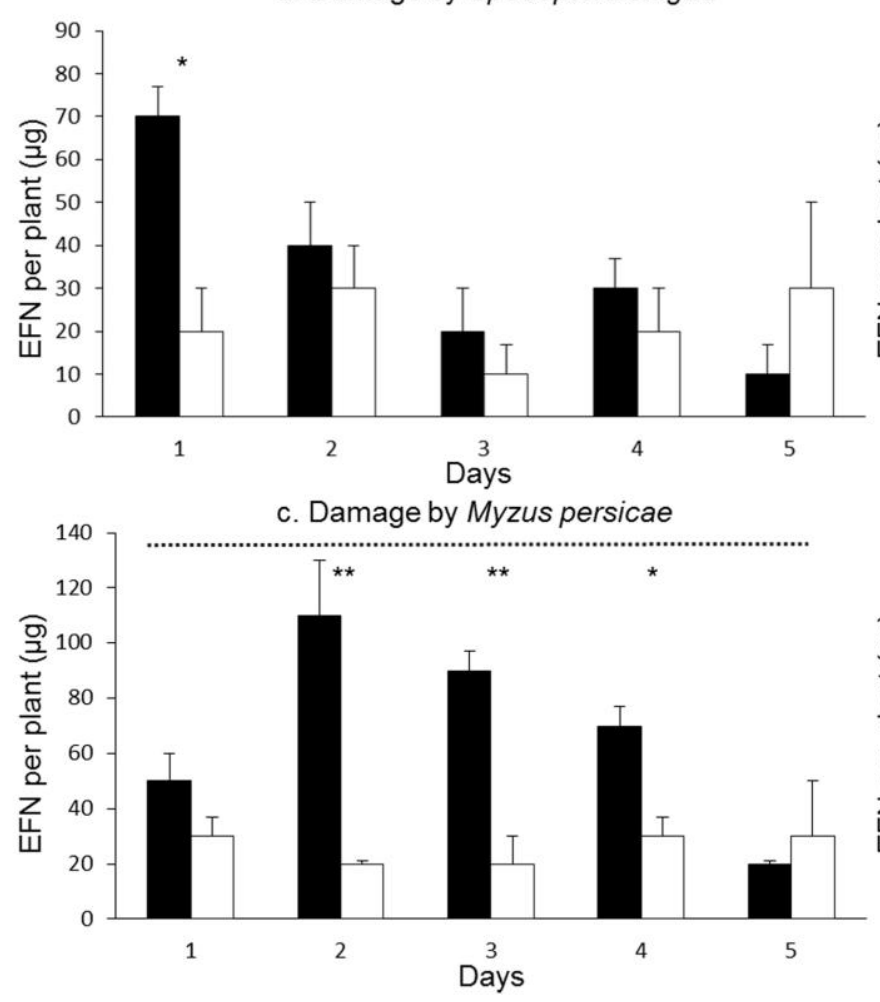

$\square$ EFN from undamaged plants

b. Damage by Pieris brassicae

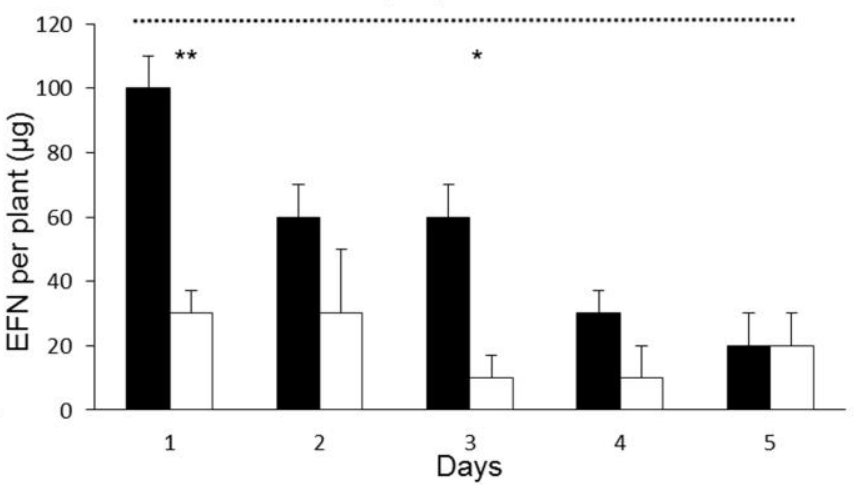

d. Damage by Delia radicum

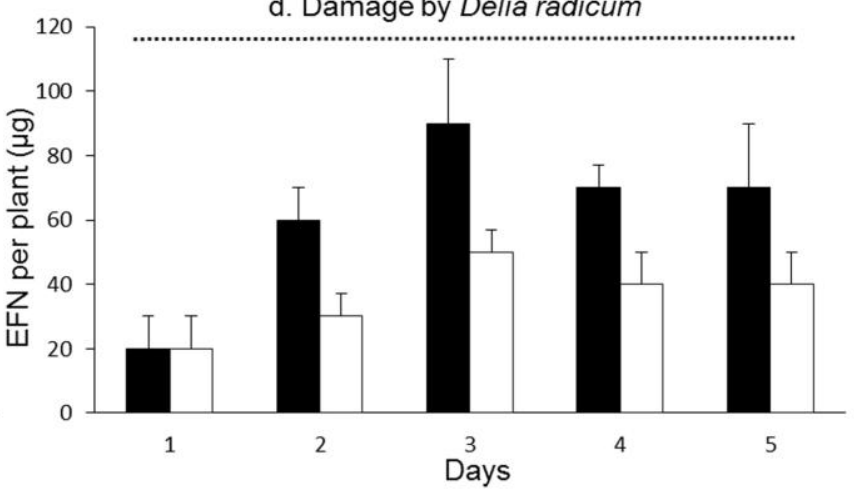




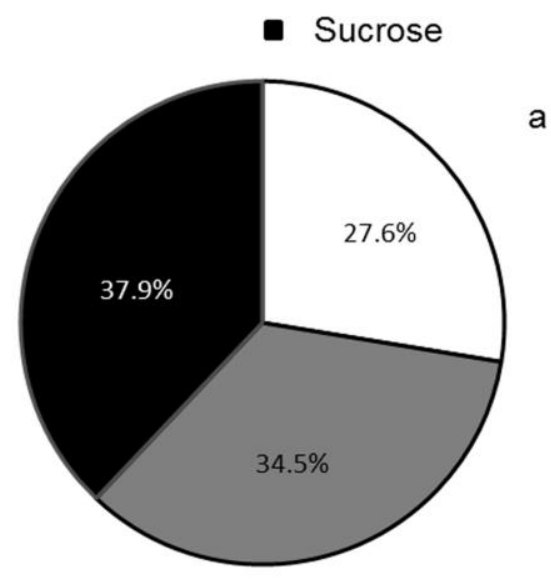

(22)

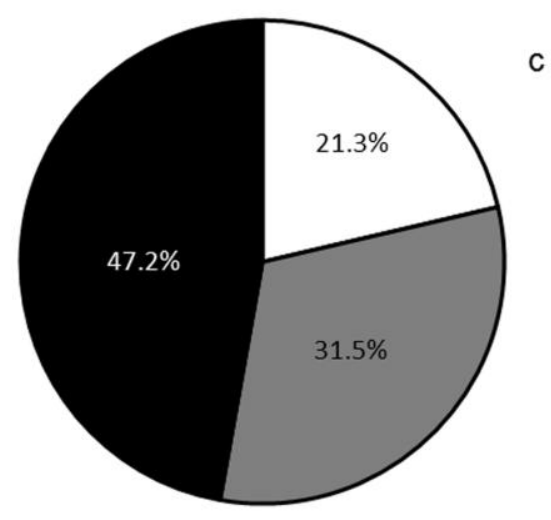

(09)
- EFN

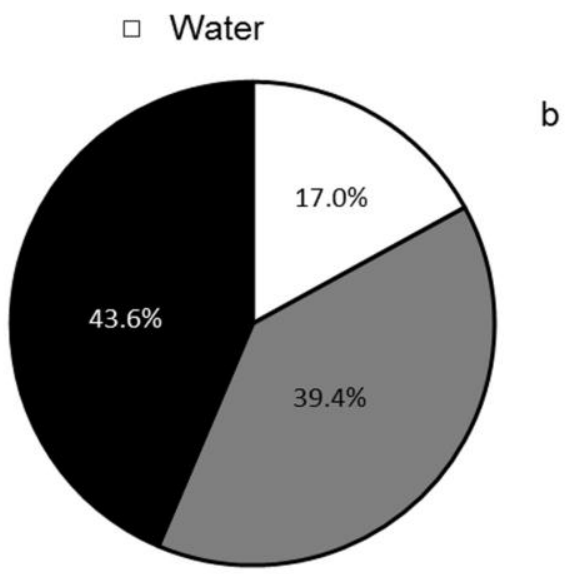

(21)

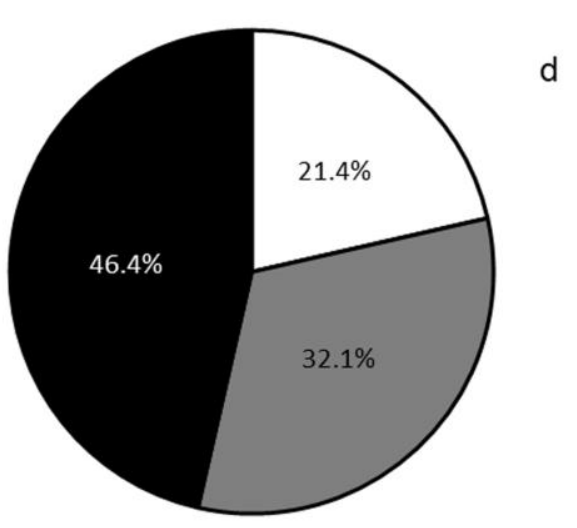

(08) 

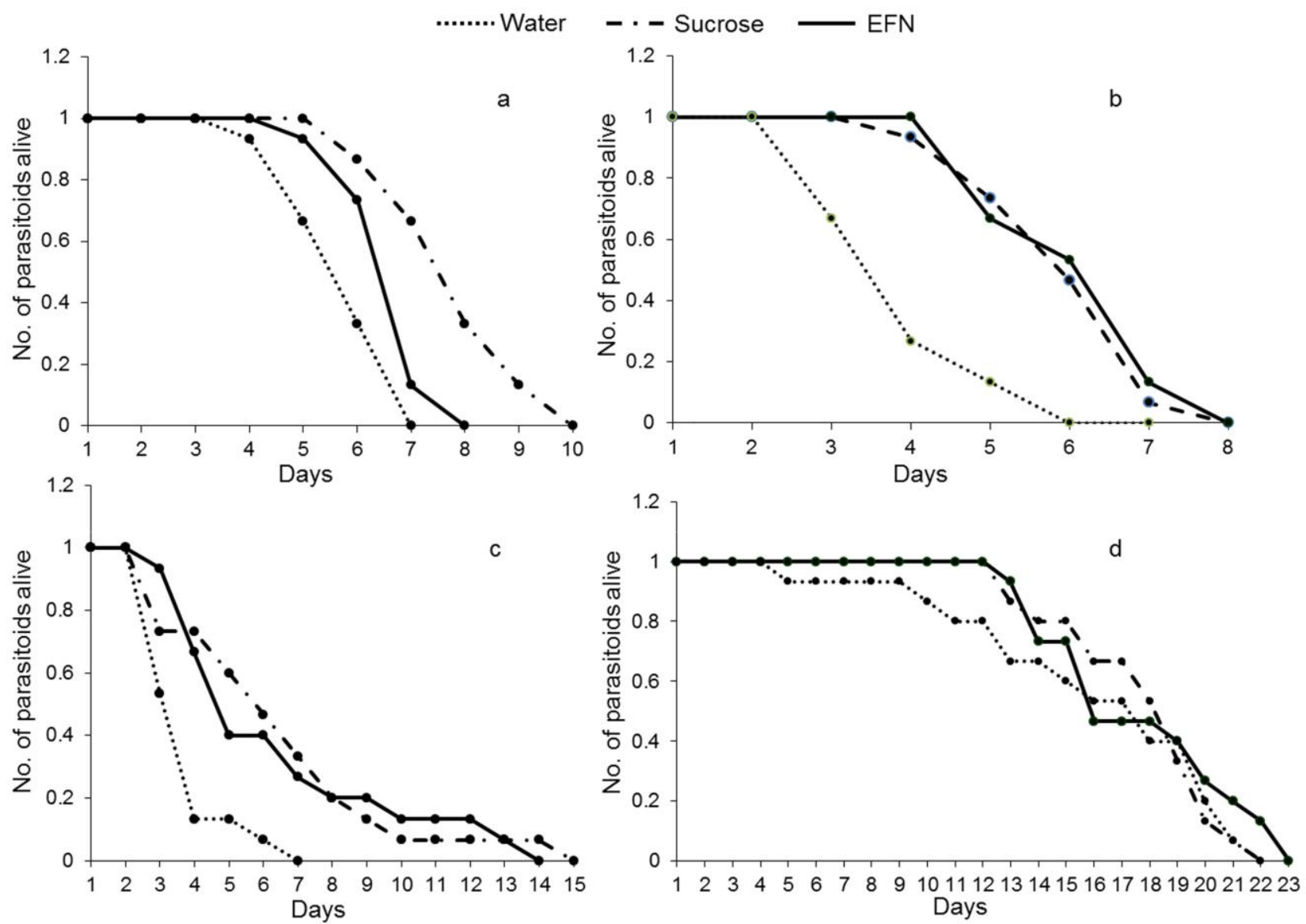